\title{
Expression and regulation effects of chemokine receptor 7 in colon cancer cells
}

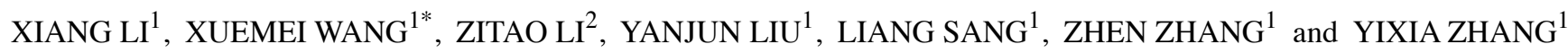 \\ ${ }^{1}$ Department of Ultrasonic Diagnosis, The First Affiliated Hospital, China Medical University, \\ Shenyang, Liaoning 110001 ; $^{2}$ Department of Orthopedic Surgery, Hongqi Hospital, \\ Mudanjiang Medical University, Mudanjiang, Heilongjiang 157011, P.R. China
}

Received May 19, 2019; Accepted December 20, 2019

DOI: $10.3892 / \mathrm{ol} .2020 .11561$

\begin{abstract}
In China the incidence and mortality rates of colon cancer have been increasing annually. Studies have revealed that CXCR7 is expressed in many tumors. The aim of the present study was to investigate the function of CXCR7 in colon cancer. The expression level of chemokine receptor 7 (CXCR7) in Caco-2 and HCT116 cells was investigated to elucidate the effect of CXCR7 on cell biological behavior. Reverse transcription-quantitative PCR and western blot analysis were used to detect the expression level of CXCR7 in Caco-2 and HCT116 cells after transfection with small interfering (si)RNA. To analyze the in vitro biological function of CXCR7, cell proliferation was measured using a Cell Counting Kit-8 assay, and cell invasion and migration were measured using Matrigel, and Transwell and wound healing assays. siRNAs were successfully transfected into Caco-2 and HCT116 cells and resulted in a decrease in CXCR7 protein and mRNA expression. Downregulation of CXCR7 inhibited Caco-2 and HCT116 cell proliferation, invasion, and migration. Regulation of CXCR7 expression may affect the biological behavior of Caco-2 and HCT116 cells, suggesting that CXCR7 has a potential role in molecular therapy in colon cancer.
\end{abstract}

\section{Introduction}

Colon cancer is one of the most common malignant tumors of the digestive system and its incidence rate is increasing every year in China $(1,2)$. The incidence rate in China was 27.08/100,000, and the mortality rate was 13.13/100,00 in 2014 (3). Patients with colon cancer typically suffer recurrence and metastasis, occasionally between 1-2 years after surgery (4).

Correspondence to: Professor Xuemei Wang, Department of Ultrasonic Diagnosis, The First Affiliated Hospital, China Medical University, 155 Nanjing North Street, Shenyang, Liaoning 110001, P.R. China

E-mail:wxmlmt@163.com

Key words: colon, CXCR7, biological behaviors of neoplasms, gene expression
It has been previously determined that chemokine receptors are involved in the development and metastasis of breast cancer, prostate cancer, colon cancer, liver cancer (5-8). Recently, there is increasing evidence that chemokines and their receptors play a key role in the development and progression of cancer (9-11). CXCL14 is expressed by islet $\delta$-cells where it may exert paracrine effects to inhibit insulin secretion in a CXCR4/CXCR7-independent manner through reductions in $\beta$-cell ATP levels (10). Zhang et al (11) revealed that angiogenesis was enhanced with increased SDF1 and that angiogenesis was weakened with the inhibition of CXCR7. They demonstrated that PI3K/AKT was involved in the downstream pathway in the coculture. VEC angiogenesis induction by NPCs was enhanced with an increase in pAKT or a decrease in PTEN. The chemokine receptor investigated in the current study is chemokine receptor 7 (CXCR7), which is a new receptor for $\mathrm{C}-\mathrm{X}-\mathrm{C}$ motif chemokine ligand 12 [CXCL12; also known as stromal cell-derived factor-1 (SDF-1)], after the discovery of the CXCR4 receptor, and its binding affinity for CXCL12 is up to 10 times higher compared with that of the CXCR4 receptor $(12,13)$.

Studies have shown that CXCR7 can inhibit tumor cell growth and proliferation in prostate cancer and neuroblastoma by binding to CXCL12 (14,15). Stacer et al (16) found that high expression of CXCR7 in endothelial cells can regulate the metastasis of breast cancer cells. A previous study revealed that CXCR7 enhances PC3 and C4-2B prostate cancer cell invasion and metastasis by regulating the expression levels of cell adhesion molecules, such as fibronectin, cadherin-11, CD44, and matrix metalloproteinases (14). A previous report demonstrated that CXCR7 is highly expressed in human colon cancer cells (17). Over the last 8 years, a number of studies have confirmed that CXCR7 is also expressed in other types of cancer, such as pancreatic cancer, thyroid cancer, prostate cancer, breast cancer, esophageal cancer, liver cancer, and bladder cancer, and it has been shown to promote tumor growth and metastasis $(5,18-23)$. The results of our previous study (24) indicated that the protein and mRNA expression of CXCR7 in Caco-2 cells was low compared with that in RKO, SW480, and HCT116 colon cancer cells. However, whether CXCR7 has similar functions in Caco-2 and HCT116 cells remains to be elucidated.

Therefore, the primary aim of the current study is to assess the protein and mRNA expression levels of CXCR7 in Caco-2 and HCT116 cells, and secondly to inhibit the expression level 
of CXCR7 in Caco-2 and HCT116 cells and investigate the subsequent biological activity of these cells.

\section{Materials and methods}

Cell culture. Caco-2 and HCT116 cells were purchased from the Cell Bank of the Chinese Academy of Sciences and cultured in Dulbecco's modified Eagle's medium (HyClone; GE Healthcare Life Sciences) containing $10 \%$ fetal bovine serum (FBS), and $100 \mathrm{U} / \mathrm{ml}$ penicillin and $100 \mu \mathrm{g} / \mathrm{ml}$ streptomycin. The cells were cultured in an incubator at $37^{\circ} \mathrm{C}$ in a humidified incubator with $5 \% \mathrm{CO}_{2}$.

Cell transfection. Caco-2 and HCT116 cells were seeded at a density of $4 \times 10^{5}$ cells/well in a 6 -well plate overnight, and the medium was replaced with fresh medium without FBS. Cy5 fluorescence-labeled siRNA (Guangzhou RiboBio Co., Ltd.) was transfected into Caco-2 and HCT116 cells by Lipofectamine 3000 . After $6 \mathrm{~h}$, the siRNA transfection efficiency was observed under the inverted fluorescence microscope. The three CXCR7 interfering segments were as follows: siRNA1, 5'-CGUCCAACAAUGAGACCUAdTdT-3'; siRNA2, 5'-CGUCCAACAAUGAGACCUAdTdT-3'; and siRNA3, 5'-GCUAUGACACGCACUGCUAdTdT-3'. siRNAs [siRNA1, siRNA2, siRNA3, and siRNA Negative Control (NC); Guangzhou RiboBio Co., Ltd.] were transfected into Caco-2 and HCT116 cells using Lipofectamine ${ }^{\circledR} 3000$ transfection reagent (Invitrogen; Thermo Fisher Scientific, Inc.), in accordance with the manufacturer's instructions. Follow-up subsequent experimentation $6 \mathrm{~h}$ after transfection.

Reverse transcription-quantitative PCR (qRT-PCR) after transfection. The total RNA of the cells was extracted using TRIzol $^{\circledR}$ reagent (Invitrogen; Thermo Fisher Scientific, Inc.), Reverse transcription of total RNA was carried out by using a Prime Script RT Master mix (Takara Biotechnology Co., Ltd.). The following primers were used: CXCR7 forward, 5'-TCTGCATCTCTTCGACTACTCA-3' and reverse 5'-GTA GAGCAGGACGCTTTTGTT-3'; GAPDH forward, 5'-GAA GGTGAAGGTCGGAGTC-3' and reverse 5'-GAAGAT GGTGATGGGATTTC-3'. GAPDH was used as the internal control. Subsequently, $1 \mu \mathrm{l}$ cDNA was amplified using $10 \mu \mathrm{l}$ SYBR Premix Ex TaqII kit (Takara Biotechnology Co., Ltd.) and $0.8 \mu \mathrm{l}$ primers in a Light Cycler 480 instrument (Roche Diagnostics). The following thermal cycling conditions were used: Initial denaturation at $95^{\circ} \mathrm{C}$ for $30 \mathrm{sec}, 45$ cycles of $95^{\circ} \mathrm{C}$ for $5 \mathrm{sec}, 60^{\circ} \mathrm{C}$ for $30 \mathrm{sec}$, melting curve at $95^{\circ} \mathrm{C}$ for $5 \mathrm{sec}$, $60^{\circ} \mathrm{C}$ for $60 \mathrm{sec}, 95^{\circ} \mathrm{C}$ for $5 \mathrm{sec}$, and cooling at $40^{\circ} \mathrm{C}$ for $30 \mathrm{sec}$. Relative mRNA expressions was calculated using the $2^{-\Delta \Delta C T}$ method: $2^{-\Delta \Delta \mathrm{CT}}(\Delta \Delta \mathrm{Ct}=[\mathrm{Ct}(\mathrm{CXCR} 7)-\mathrm{Ct}(\mathrm{GAPDH})]$ target[Ct (CXCR7)-Ct (GAPDH)]xinternal standard (25).

Western blot analysis. Transfected cells were incubated in radioimmunoprecipitation assay (RIPA) buffer (Beyotime Institute of Biotechnology) for $15 \mathrm{~min}$. The protein concentration of the samples was calculated using a bicinchoninic acid (BCA) protein concentration assay kit. Each sample (20 mg/lane) was mixed with loading buffer (Beyotime Institute of Biotechnology) and boiled for $5 \mathrm{~min}$ at $95^{\circ} \mathrm{C}$ in the heating module. Then, $20 \mathrm{mg}$ per lane of proteins from each sample were loaded and separated by $10 \%$ sodium dodecyl sulfate-polyacrylamide gel electrophoresis (SDS-PAGE), later transferred to polyvinylidene difluoride membranes (PVDF; Bio-Rad Laboratories, Inc.). The membranes were blocked at room temperature for $2 \mathrm{~h}$ with $3 \%$ bovine serum albumin (BSA, Hyclone; GE Healthcare Life Sciences) and washed them three times with TBST. The dilution ratio for the anti-CXCR7 antibody (cat. no. ab72100) was 1:1,000 and for the anti-GAPDH antibody (cat. no. ab181602) was 1:2,000 (both Abcam). The primary antibody was incubated overnight at $4^{\circ} \mathrm{C}$. After several washings, membranes were incubated with horseradish peroxidase-conjugated secondary antibody (anti-rabbit) $(1: 2,000$ dilution) for $2 \mathrm{~h}$ at $37^{\circ} \mathrm{C}$. The protein bands were developed by adding ECL solution (Bio-Rad Laboratories, Inc.). The levels of protein expression were evaluated by Image Pro Plus 6.0 (IPP) software (Media Cybernetics, Inc.).

Immunofluorescence assay after transfection. The cells were washed three times with phosphate-buffered saline (PBS), fixed with $4 \%$ paraformaldehyde for $20 \mathrm{~min}$ at RT, and incubated with $0.1 \%$ Triton X-100 penetrant for 25 min. After washing the well plates, the samples were blocked in goat serum (HyClone; GE Healthcare Life Sciences) for $30 \mathrm{~min}$ at RT, and incubated with CXCR7 antibody (cat. no. ab72100; dilution 1:100; Abcam) overnight at $4^{\circ} \mathrm{C}$. Subsequently, the cells were incubated with fluorescent secondary antibody (1:200) for $1 \mathrm{~h}$ at $37^{\circ} \mathrm{C}$, washed three times with PBS, incubated with 4',6-diamidino-2-phenylindole for $30 \mathrm{~min}$ at RT, and images were obtained using a fluorescence microscope (magnification, x200). The levels of fluorescence intensity were evaluated by Image Pro Plus 6.0 (IPP) software.

Cell Counting Kit-8 (CCK-8) and 5-ethynyl-2'-deoxyuridine (EdU) assays to detect cell proliferation after transfection. Cells were seeded in 96-well plates at 5,000 cells per well. After 24, 48 and $72 \mathrm{~h}$ of culture, $100 \mu \mathrm{l}$ of Dulbecco's Modified Eagle Medium (DMEM) medium (HyClone; GE Healthcare Life Sciences) containing 10\% CCK-8 reagent (Dojindo Molecular Technologies) was added to each well, in accordance with the manufacturer's instructions. The plates were incubated at $37^{\circ} \mathrm{C}$ for 1 and $2 \mathrm{~h}$, and then, the absorbance was measured at $450 \mathrm{~nm}$ using a microplate reader (Thermo Fisher Scientific, Waltham, MA, USA). Next, $50 \mu \mathrm{M}$ EdU medium was prepared, and $200 \mu \mathrm{l}$ of the medium was added to each well for $2 \mathrm{~h}$. The wells were then subjected to Apollo staining for $30 \mathrm{~min}$ at RT, in accordance with the manufacturer's instructions, and images were obtained using a fluorescence microscope (magnification, x200).

Cell migration and invasion assay after transfection. The transfected cells were seeded into the upper chamber of a Transwell insert at a density of $4 \times 10^{5}$ cells/well without FBS, and $500 \mu \mathrm{l}$ of DMEM (HyClone; GE Healthcare Life Sciences) containing $20 \%$ FBS was added to the lower chamber; the chambers were then incubated at $37^{\circ} \mathrm{C}$ for $6 \mathrm{~h}$. The migrant cells that were adhered to the lower surface of the membrane were fixed with $4 \%$ paraformaldehyde for $20 \mathrm{~min}$ at room temperature, and then stained with $0.1 \%$ crystal violet for 30 min at RT. The number of cells under the membrane surface was counted in five different fields using a light microscope at a magnification of $\mathrm{x} 200$. Transfected Caco- 2 and HCT116 cells 
A

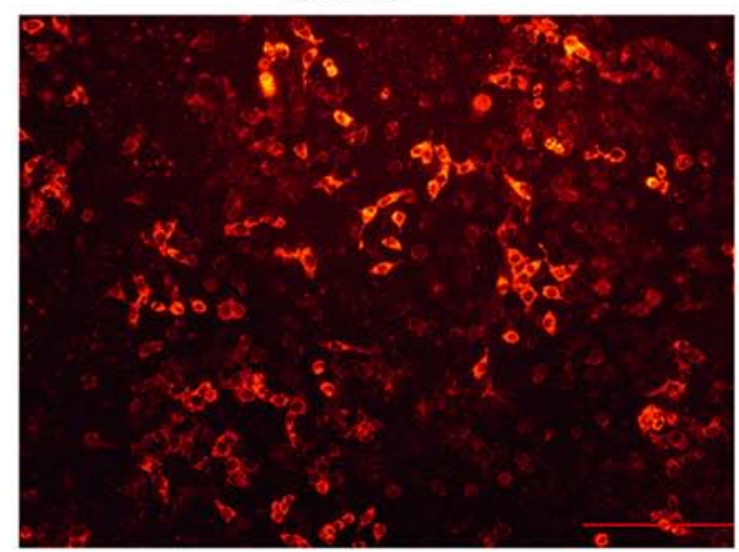

B

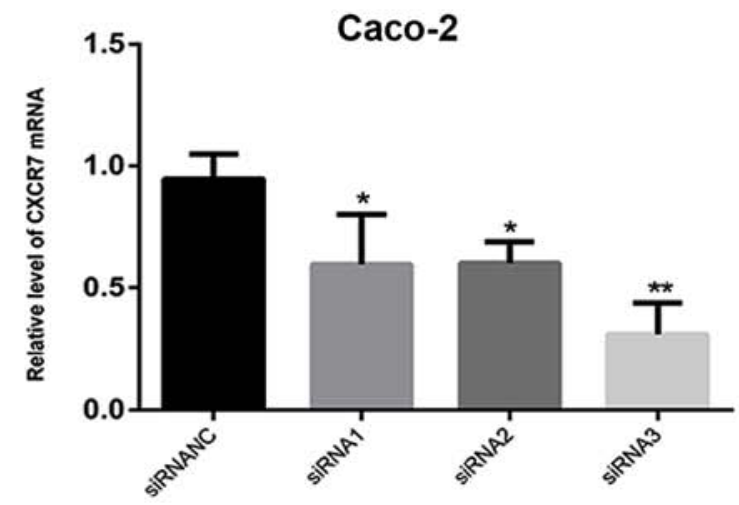

C
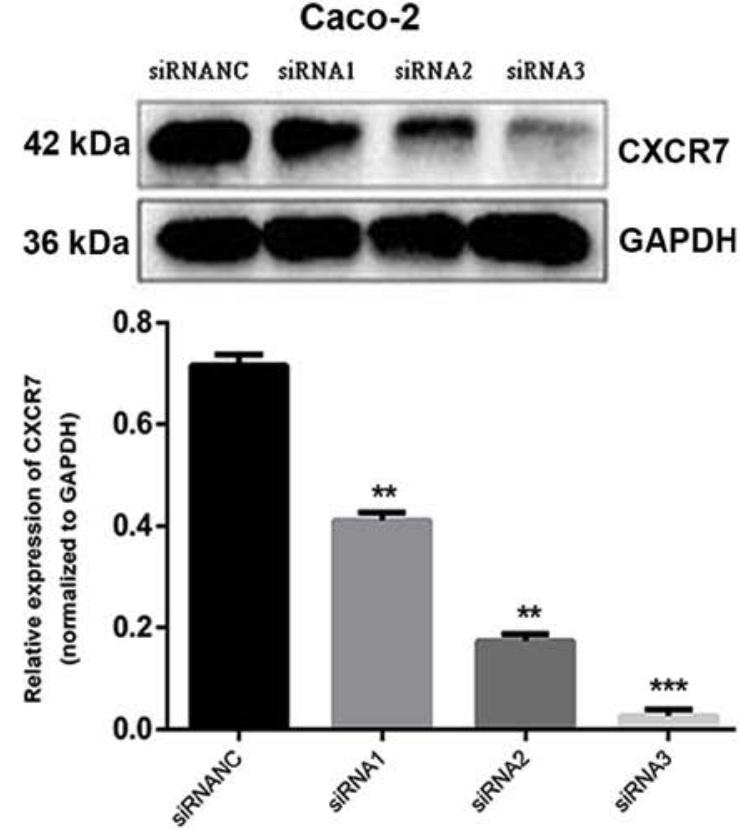

HCT116
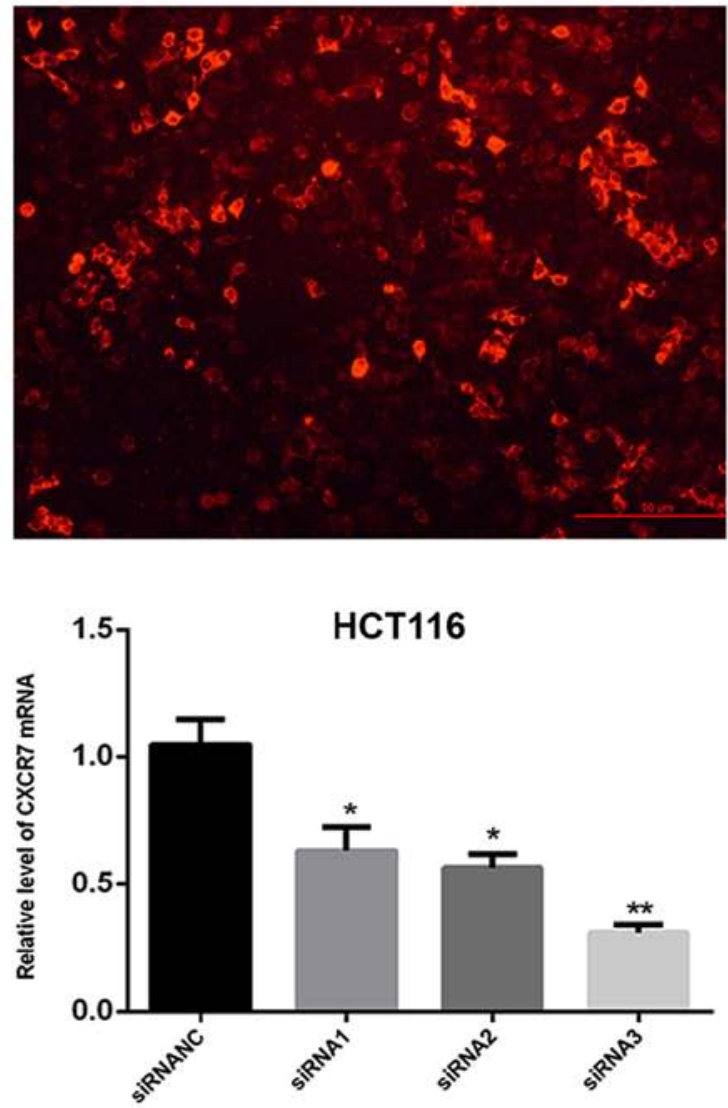

HCT116
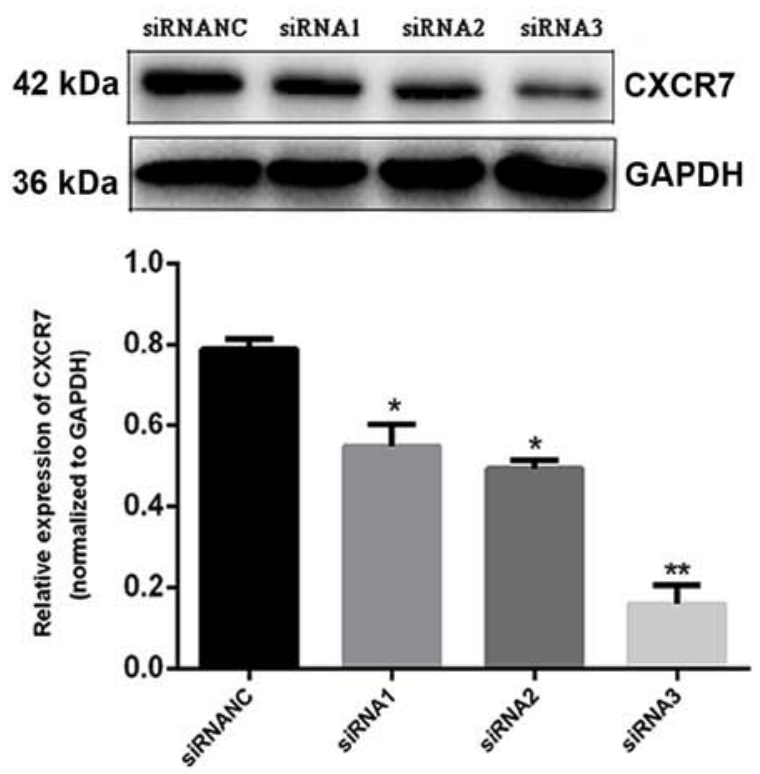

Figure 1. Expression level of CXCR7 in colon cancer cells following transfection. (A) Fluorescence microscopy confirmed that the transfection efficiency of fluorescent control-transfected Caco-2 and HCT116 cells was high (magnification, x200). (B) Reverse transcription-quantitative PCR detection of mRNA expression, (C) representative image of western blot analysis and quantitative analysis of protein expression, in Caco-2 and HCT116 cells.

were seeded into 6-well plates at a density of $4 \times 10^{5}$ cells/well prior to a wound healing assay. When the confluence of cells was $>90 \%$, a scratch was created using a $10 \mu 1$ pipette tip in the middle of the well. Cells were cultured with serum-free medium for a further 24,48 and $72 \mathrm{~h}$. A light microscope was used to observe wound healing (magnification, $\mathrm{x} 200$ ). Matrigel (100 $\mu \mathrm{l}$; 1:6 dilution; BD Biosciences) was added to the upper chamber to coagulate for $30 \mathrm{~min}$ at $37^{\circ} \mathrm{C}$, and cells were cultured for $24 \mathrm{~h}$ for invasion experiments. The additional steps were the same as aforementioned. 
D
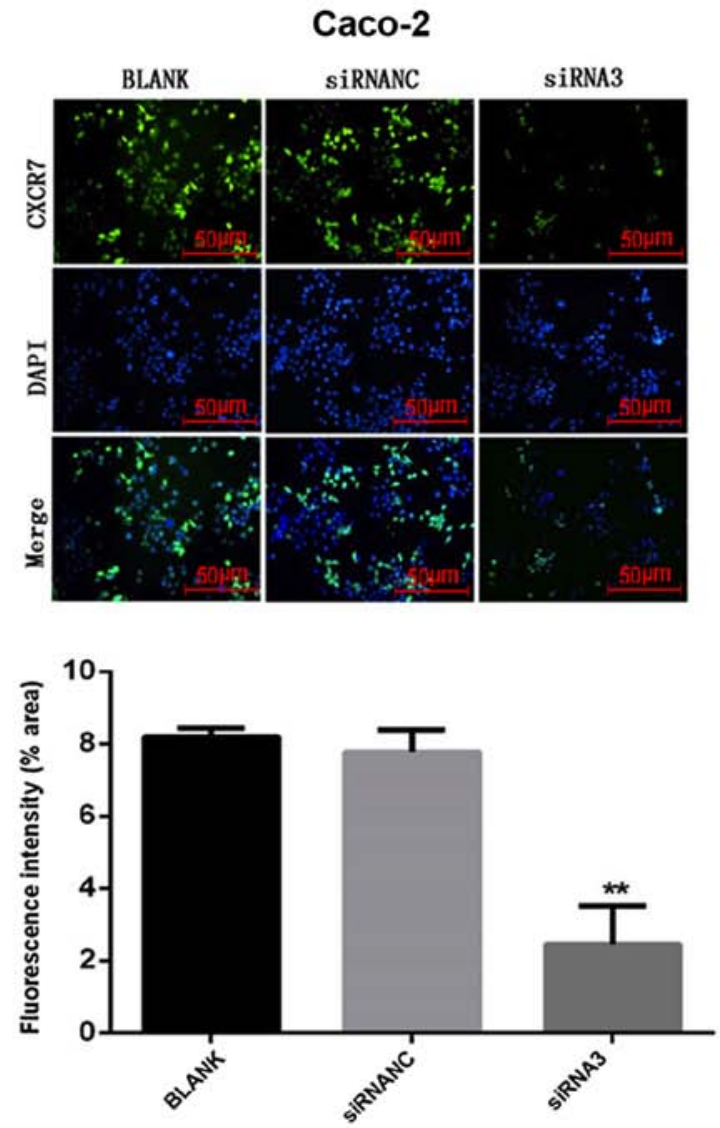

HCT116
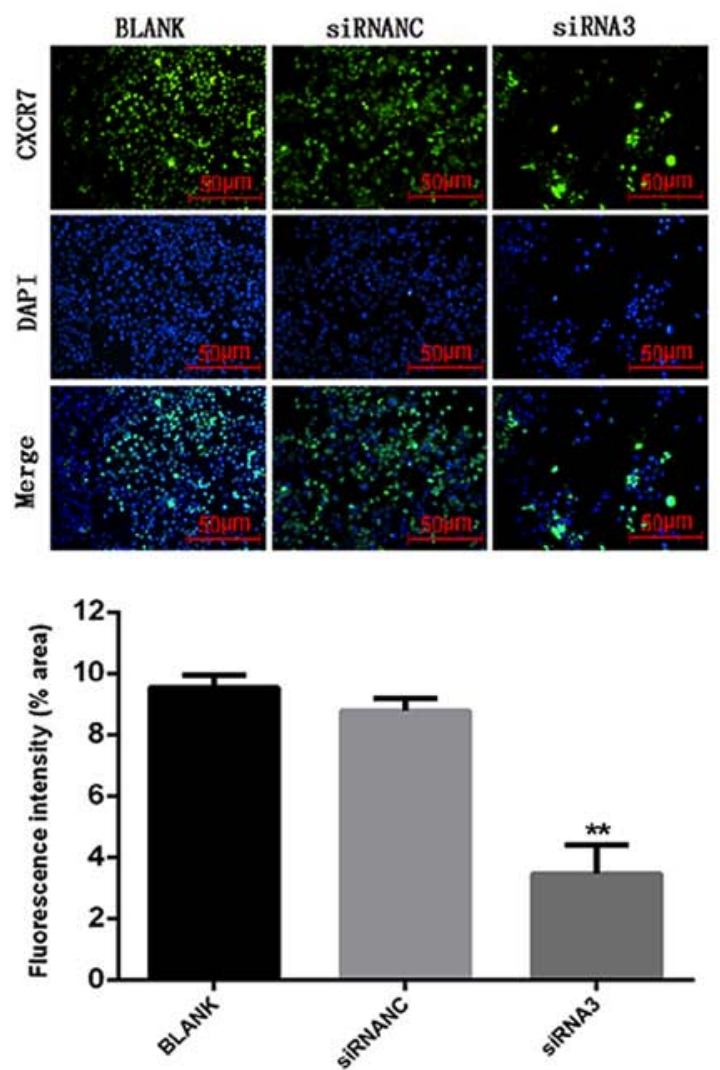

Figure 1. Continued. Expression level of CXCR7 in colon cancer cells following transfection. (D) Fluorescent images of cells following transfection with siRNA3 and quantitative analysis of immunofluorescence expression. ${ }^{*} \mathrm{P}<0.05 ;{ }^{* *} \mathrm{P}<0.01 ;{ }^{* * *} \mathrm{P}<0.001$ vs. siRNANC groups. CXCR7, chemokine receptor 7 ; siRNA, small interfering RNA; NC, negative control.

Statistical analysis. All data are expressed as the mean \pm standard deviation. Statistical differences between the groups were assessed using SPSS version 19.0 software (IBM Corp.). Differences between groups were calculated using a one-way analysis of variance (ANOVA), and $\mathrm{P}<0.05$ was considered to indicate a statistically significant difference. The experiment above was performed in triplicate.

\section{Results}

Expression level of CXCR7 in Caco-2 and HCT116 cells after transfection. siRNA1, siRNA2, siRNA3, and siRNANC were transfected into Caco-2 and HCT116 cells, and fluorescence imaging confirmed that the transfection was effective (Fig. 1A). In the present study, RT-qPCR and western blot analysis showed that the expression level of CXCR7 in the transfected group (siRNA3) was significantly lower compared with that in the NC group (qPCR: Caco-2, 0.87 \pm 0.11 and HCT116, 1.05 \pm 0.10 ; WB: Caco-2, 0.69 \pm 0.03 and HCT116, $0.79 \pm 0.03$ ), and the effect of siRNA3 (PCR: Caco-2, 0.34 \pm 0.15 and HCT116, 0.31 \pm 0.03 ; WB: Caco-2, 0.06 \pm 0.02 , and HCT116, $0.16 \pm 0.05$ ) was the most significant in reducing CXCR7 expression. Consequently, siRNA3 was used in subsequent experiments (Fig. 1B and C).

Immunofluorescence detection following transfection. siRNA3 and siRNANC were transfected into Caco-2 and
HCT116 cells, and the expression of CXCR7 was detected. The results showed that the fluorescence intensity of Caco-2 and HCT116 cells in the siRNA3 transfected group (Caco-2, $2.12 \pm 0.14$ and HCT116, 3.45 \pm 0.95$)$ was significantly lower compared with that in the NC group (Caco-2, 7.88 \pm 0.55 and HCT116, 8.78 $\pm 0.41, \mathrm{P}<0.01)$, and the difference between the control and the NC group was not significant (Fig. 1D).

Effect of CXCR7 on the proliferation of Caco-2 and HCT116 cells. Following transfection of siRNA3 into Caco-2 and HCT116 cells, their proliferation was measured using CCK-8 and EdU assays. After 48 and 72 h, $10 \mu \mathrm{l} \mathrm{CCK-8} \mathrm{solution} \mathrm{was}$ added to each well and incubated for $1 \mathrm{~h}$. The CCK- 8 assay demonstrated that the proliferation of the siRNA3-transfected cells (48 h: Caco-2, 0.31 \pm 0.02 and HCT116, 0.58 \pm 0.04 ; 72 h: Caco-2, $0.67 \pm 0.06$ and HCT116, 0.73 \pm 0.06$)$ was reduced compared with that in the NC group (48 h: Caco-2, $0.65 \pm 0.03$ and HCT116, 0.75 $\pm 0.08 ; 72 \mathrm{~h}:$ Caco-2, 0.89 \pm 0.09 and HCT116, 0.93 \pm 0.06 ) (Fig. S1). After 48 and 72 h, $10 \mu 1$ CCK-8 solution was added to each well and incubated for $2 \mathrm{~h}$. The CCK- 8 assay demonstrated that the proliferation of the siRNA3-transfected cells (48 h: Caco-2, 0.45 \pm 0.05 and

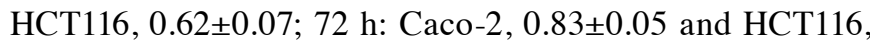
$0.89 \pm 0.06)$ was reduced compared with that in the NC group

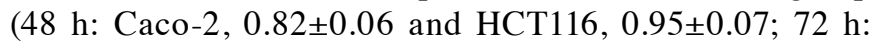

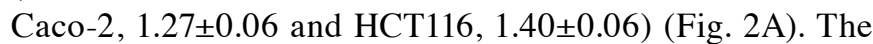
CCK-8 assay results were not statistically significant at $24 \mathrm{~h}$, 
A

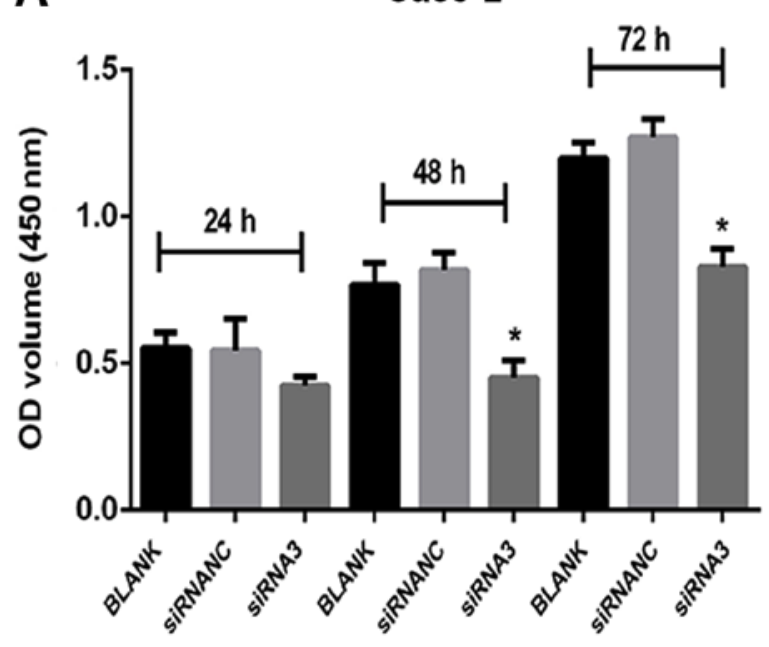

B
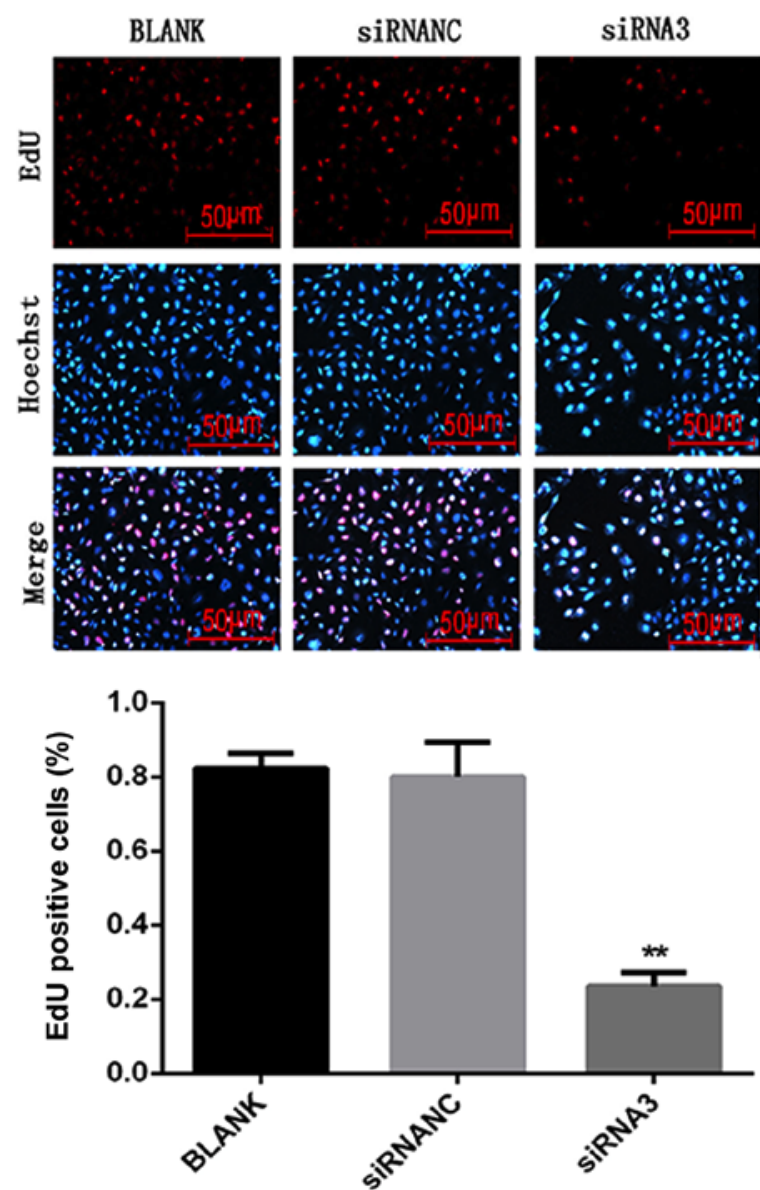

Caco-2

SIRNANC
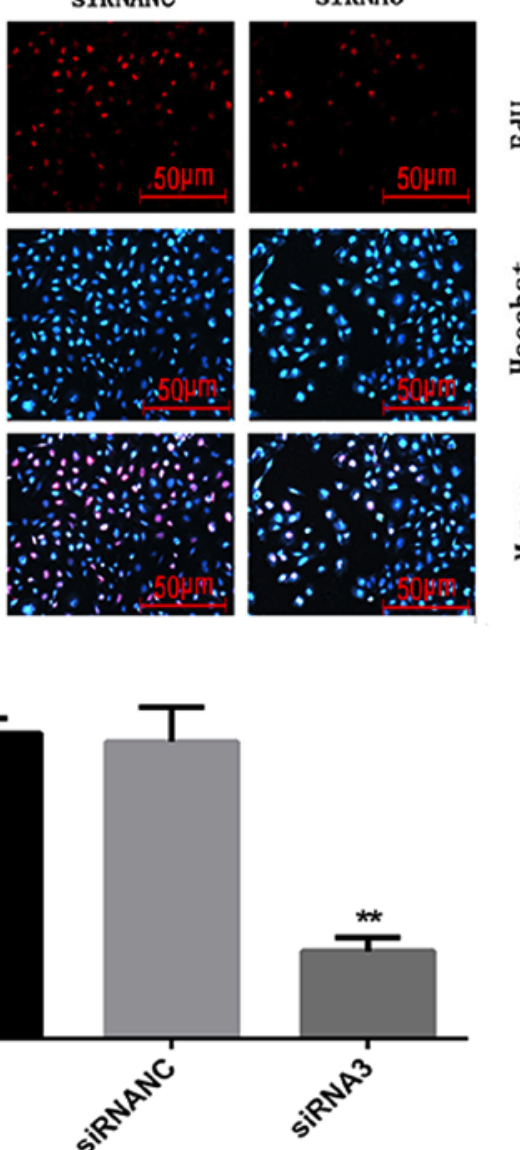

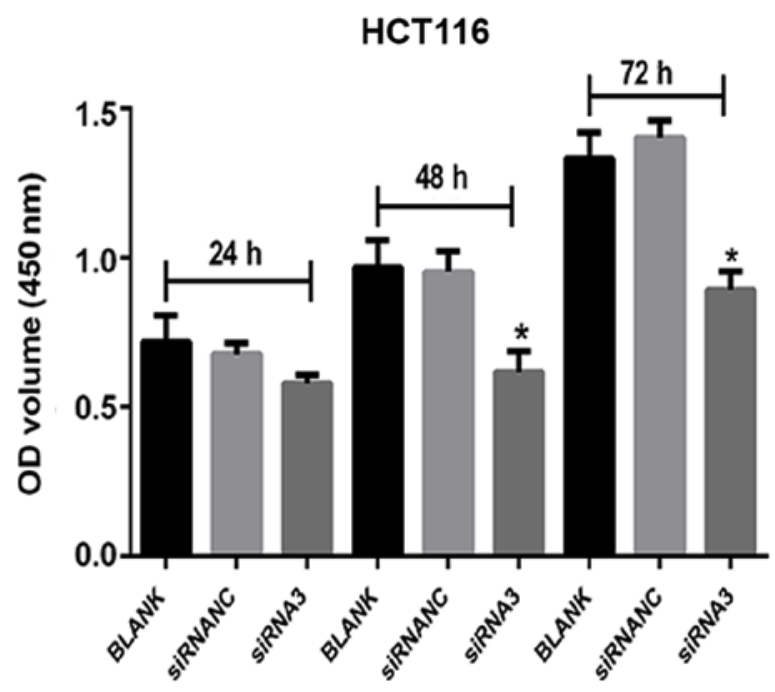

HCT116

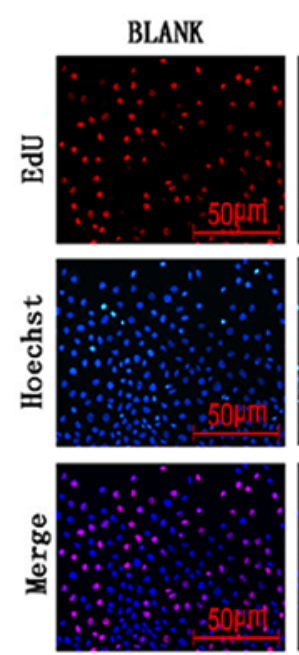

SIRNANC
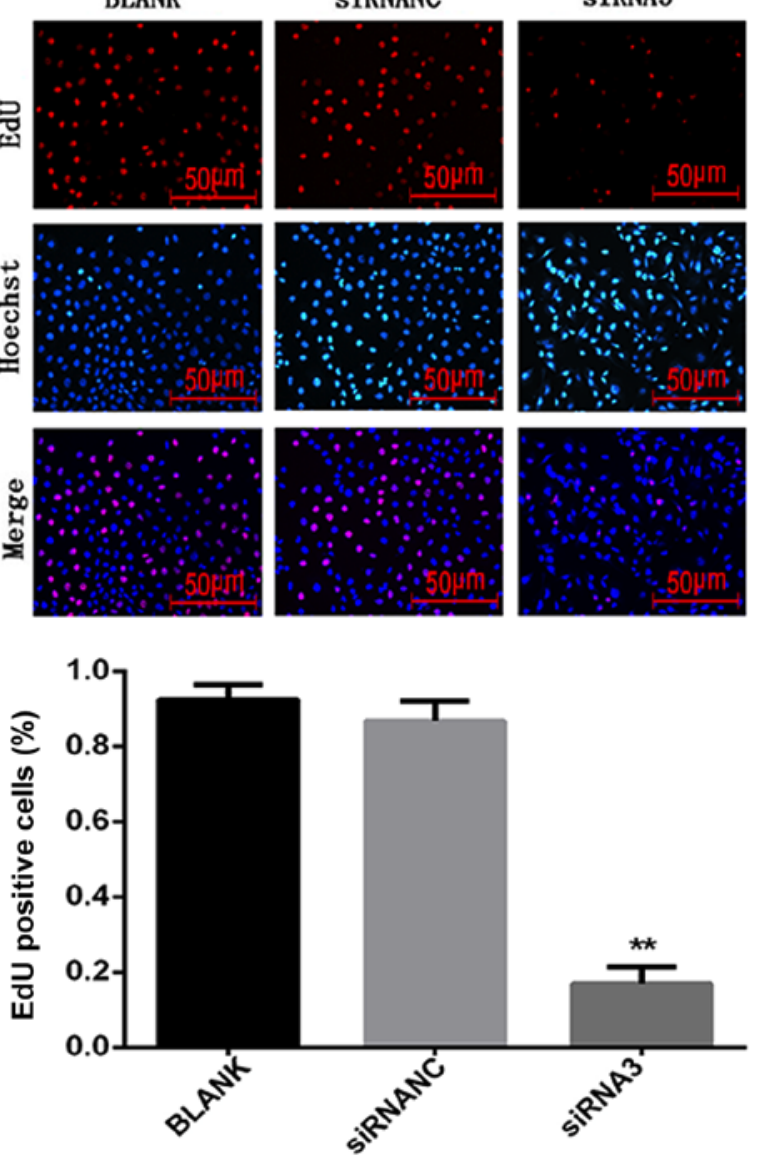

Figure 2. CCK-8 and EdU assay detects proliferation of Caco-2 and HCT116 cells. (A) The effect of siRNA3 on the proliferation of Caco-2 and HCT116 colon cancer cells was determined using the CCK-8 cytotoxicity assay and measuring the OD value of the cells at $450 \mathrm{~nm}$. (B) Representative images of the EdU assay of Caco-2 and HCT116 cells transfected with siRNA3. Quantitative measurement of EdU-positive cells indicates that silencing of CXCR7 reduces cell proliferation. ${ }^{*} \mathrm{P}<0.05 ;{ }^{* *} \mathrm{P}<0.01$ vs. siRNANC groups. CCK-8, Cell Counting Kit-8; EdU, 5-ethynyl-20-deoxyuridine; OD, optical density; siRNA, small interfering RNA; NC, negative control.

for either cell line. The EdU results revealed that the number of proliferating cells was significantly reduced $(\mathrm{P}<0.05)$ after siRNA3 transfection (Caco-2, 0.24 \pm 0.04 and HCT116, $0.17 \pm 0.04)$ compared with the NC group (Caco-2, 0.80 \pm 0.09

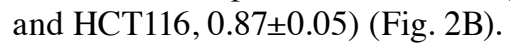

Effect of CXCR7 on the migration of Caco-2 and HCT116 cells. Following transfection of siRNA3 into Caco-2 and HCT116 cells, their migration ability was determined using a wound healing and Transwell assays. The wound healing assay results revealed that the cell migration area was 
A
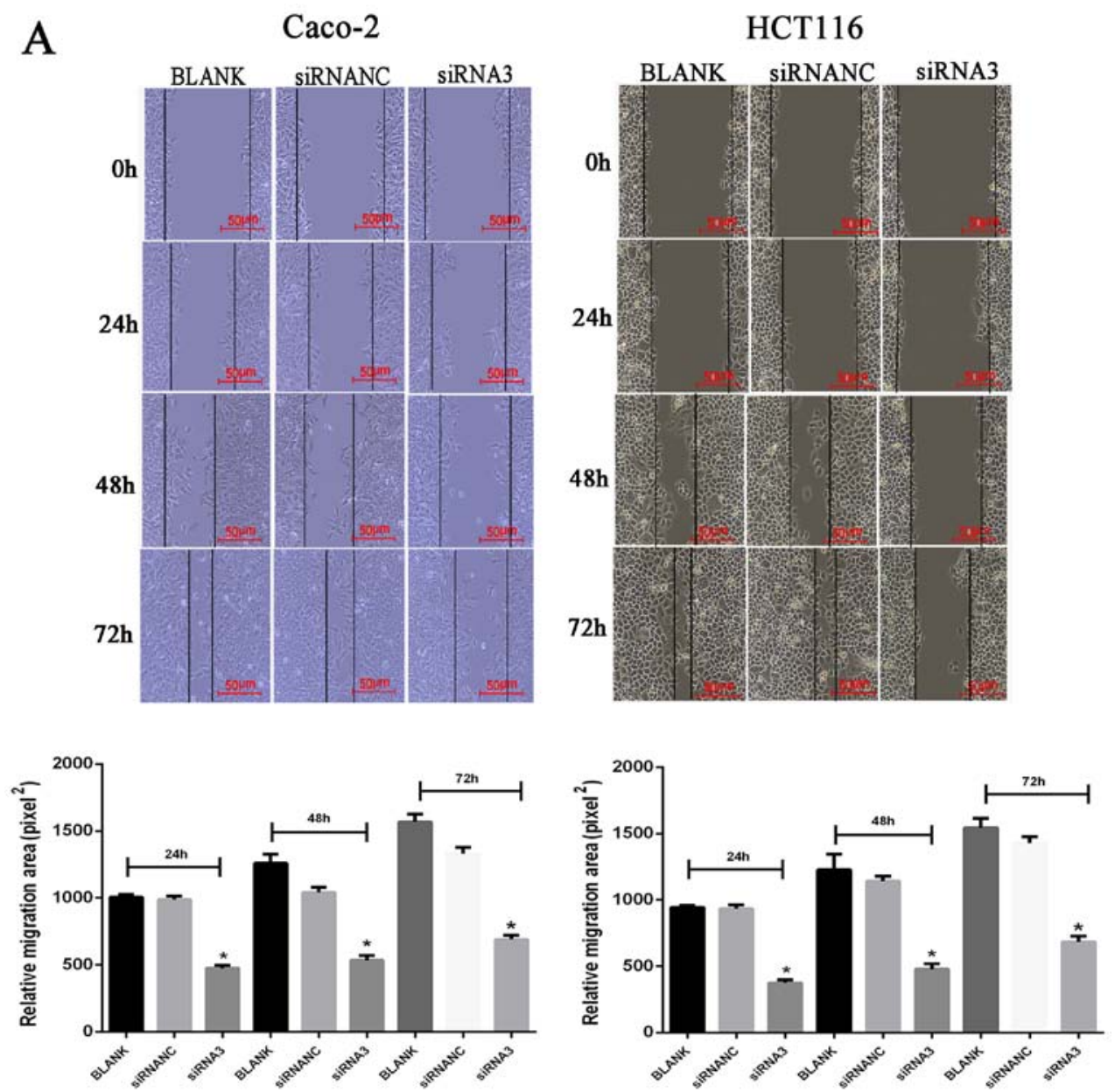

B

Caco-2

\section{HCT116}

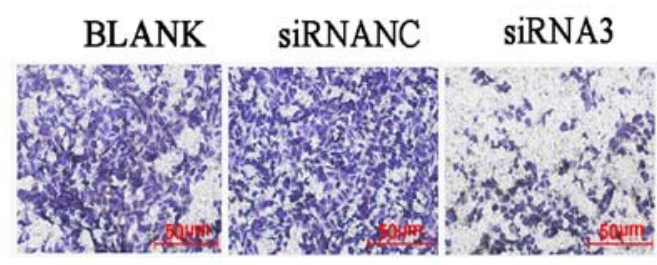

BLANK

siRNANC

siRNA3
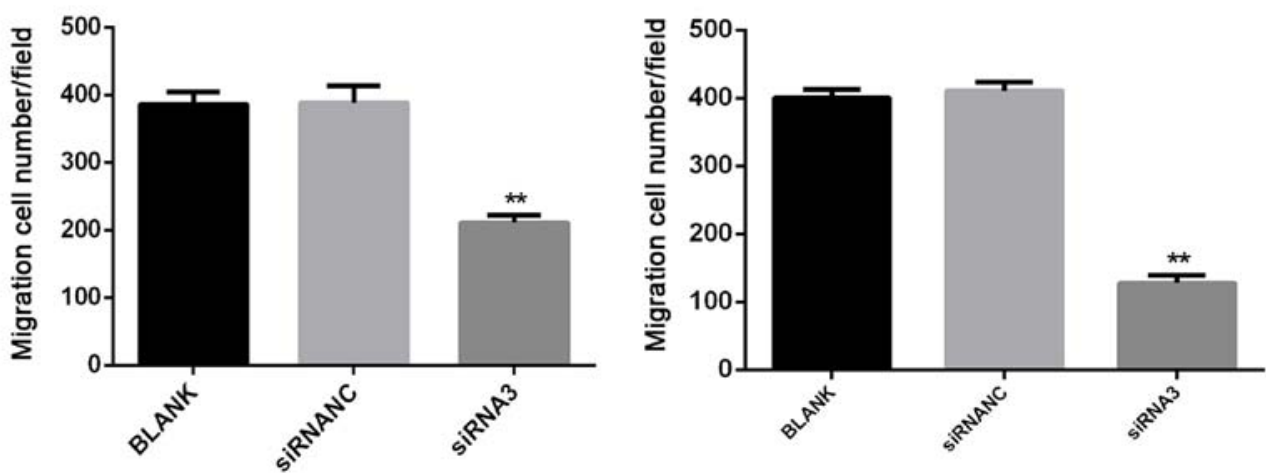

Figure 3. Wound healing and Transwell assay detects migration of Caco-2 and HCT116 cells. (A) Representative images of the wound healing assay of Caco-2 and HCT116 cells transfected with siRNA3. Quantitative measurement of the migration area indicates that silencing of CXCR7 reduces cell migration. (B) Representative image of the Transwell analysis of Caco-2 and HCT116 cells. Quantitative measurement of the number of transmembrane cells indicates that silencing of CXCR7 reduces cell migration. ${ }^{*} \mathrm{P}<0.05 ;{ }^{* *} \mathrm{P}<0.01$ vs. siRNANC groups. siRNA, small interfering RNA; NC, negative control.

significantly decreased $(\mathrm{P}<0.05)$ after Caco-2 and HCT116 transfection of siRNA3 $(24 \mathrm{~h}$ : Caco-2, $460.58 \pm 46.88$

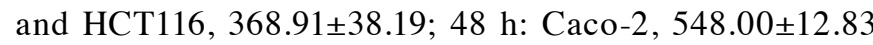

and HCT116, 471.33 $\pm 33.37 ; 72 \mathrm{~h}:$ Caco-2, $713.33 \pm 19.55$ and HCT116, 666.67 \pm 42.92 ) compared with that in the NC group (24 h: Caco-2, 944.65 \pm 53.11 and HCT116, 931.31 \pm 23.39 ; 

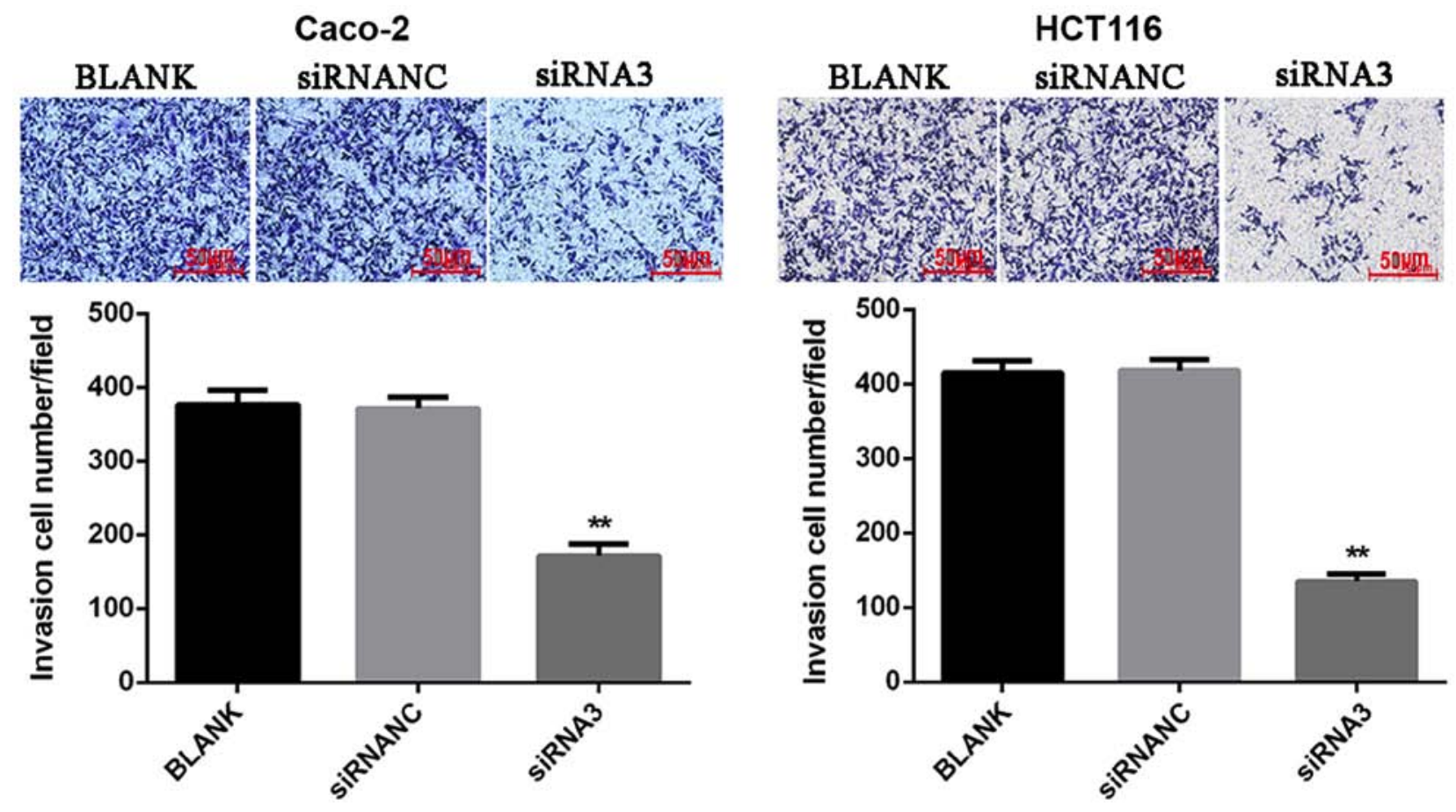

Figure 4. Effect of CXCR7 on Caco-2 and HCT116 cell invasion. Representative image of the Matrigel analysis of Caco-2 and HCT116 cells. Quantitative measurement of the number of transmembrane cells indicates that silencing of CXCR7 reduces cell invasion. ${ }^{* *} \mathrm{P}<0.01$ vs. siRNANC groups. siRNA, small interfering RNA; NC, negative control.

48 h: Caco-2, 1,060.67 $\$ 38.06$ and HCT116, 1,194.00 \pm 75.45

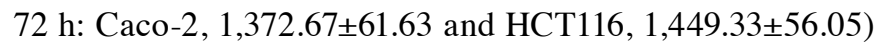
(Fig. 3A). The Transwell assay results revealed that the number of transmembrane cells was significantly decreased $(\mathrm{P}<0.01)$ after Caco-2 and HCT116 transfection of siRNA3

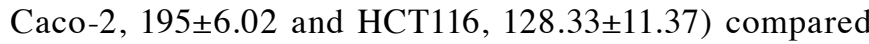
with that in the NC group (Caco-2, 389.67 \pm 22.15 and HCT116, 411.43 \pm 12.53$)$, indicating that downregulation of CXCR7 expression significantly inhibited cell migration (Fig. 3B).

Effect of CXCR7 on Caco-2 and HCT116 cell invasion. To determine the cell invasion ability, a Matrigel assay was used to detect the number of transmembrane cells. The results showed that the number of invasions of Caco-2 and HCT116 cells transfected with siRNA3 (Caco-2, 172.33 \pm 14.32 and HCT116, 135.67 \pm 10.02$)$ was significantly reduced $(\mathrm{P}<0.01)$ compared with that in the NC group (Caco-2, 371.33 \pm 15.82 and HCT116 418.33 \pm 14.19$)$. This suggests that downregulation of CXCR7 may inhibit cell invasion (Fig. 4).

\section{Discussion}

The development of cancer is a complex process, including proliferation, migration, and invasion (26). Previous studies have found that chemokines and chemokine receptors play an important role in tumor invasion, growth, and metastasis (27,28). Romain et al (29) found that the mRNA or protein expression of CXCR4 and CXCR7 was similar to that of the normal mucosa in the polyps and early-stage carcinomas but significantly increased in late stage carcinomas.

Recent studies have reported that another receptor for SDF-1, CXCR7, is overexpressed in various human malignancies, such as ovarian cancer, colorectal cancer, and breast cancer $(7,30,31)$. Experimental studies showed that mice treated with anti-SDF-1 showed higher expression of CXCR7 compared with that in controls, indicating that CXCR7 regulates colon cancer angiogenesis and tumor growth independently of SDF-1 (32). Moreover, a previous study revealed that the chemokine receptor CXCR7 demonstrates increased expression in colorectal cancer tumors (33). Guillemot et al (34) suggested that the activation of CXCR7 on tumor blood vessels by its ligands may facilitate the progression of CRC within lung cancer but not within liver cancer. Wang et al (35) found that CXCR7-knockdown negatively affected cell survival and migration in vitro, suggesting that CXCR7 functions in tumor aggravation. The experiments performed in the present study also demonstrated the proliferation, invasion and migration ability of Caco-2 and HCT116 cells was significantly reduced following transfection with CXCR7 siRNA, inhibiting the tumor-like behavior of these cells, which supports the previous studies.

In the present study, downregulation of CXCR7 expression has been shown to inhibit tumor cell proliferation, migration, and invasion. The CCK-8 assay and EdU results revealed that cell proliferation was reduced after transfection compared with that in the NC group. The wound healing assay and Transwell assay results revealed that the migration area and the number of migrating cells were significantly reduced in the siRNA3 transfection group compared with that in the NC group. In our previous study (24), SW480 and Caco-2 cells were inoculated subcutaneously into the right lower limb tissue of mice. CXCR7 was upregulated or downregulated prior to inoculation in mice. The expression of CXCR7 was measured using RT-qPCR, western blot analysis, and immunohistochemistry. Firstly, RT-qPCR and western blot analysis revealed that knockdown 
of CXCR7 in SW480 and Caco-2 cells decreased the phosphorylation of AKT and ERK and expression of VEGF. In contrast, overexpression of CXCR7 in SW480 and Caco-2 cells increased the phosphorylation of AKT and ERK and expression of VEGF. Secondly, the immunohistochemical staining was higher in CXCR7-overexpressing Caco-2 cells compared with that in the $\mathrm{NC}$ group. In contrast, the staining was lower in the CXCR7-silenced SW480 cells compared with that in the NC group. These results indicate that CXCR7 simultaneously regulates the ERK/AKT signaling pathway and expression of VEGF in colon cancer in vitro and in vivo. Our previous study revealed that CXCR7 is a key factor in tumorigenesis by promoting cell proliferation and angiogenesis (24). The results of the present study support the current conclusions and also indicate that changes in the expression of CXCR7 are key factors in the development and progression of colon cancer. The effects of CXCR7 on colon cancer migration and invasion was further investigated. The results showed that silencing CXCR7 also inhibits colon cancer migration and invasion. Wang et al (36) found that CXCR7 is involved in CXCL12 cell cycle and proliferation regulation in mouse neural progenitor cells, and CXCL12 pretreatment leads to shortening of the $G_{0} / G_{1}$ phase and prolongation of $\mathrm{S}$ phase, and increases cyclin $\mathrm{D} 1$ and $\beta$-catenin expression. Notably, in vitro experiments performed by Kim et al (37) on U937 cell migration revealed that the silencing of CXCR7 did not change the proliferation or apoptosis of U937 cells. This indicates that the effect of dysregulation of CXCR7 expression is specific to different cancer types.

A previous study has shown that a CXCR7 antagonist (CCX771) inhibits tumor growth and metastasis in a mouse breast cancer model (22). Lin et al (38) also found that CCX771 can inhibit the proliferation of HepG2 hepatoma cells overexpressing CXCR7 by blocking the activated mitogen activated protein kinase signaling pathway. The results of the current study indicate that downregulation of CXCR7 expression inhibits cell proliferation, invasion, and migration. Gebauer et al (39) found that the high expression of CXCR7 in colorectal cancer is associated with poor prognosis in patients. Therefore, inhibition of CXCL12/CXCR7 may represent a new approach for tumor targeted therapy.

\section{Acknowledgements}

Not applicable.

\section{Funding}

This study was supported by the Heilongjiang Provincial Science Fund Project (grant no. H2017078).

\section{Availability of data and materials}

The datasets used and analyzed during the current study are available from the corresponding author on reasonable request.

\section{Authors' contributions}

XL contributed to collecting data, data analysis and interpretation, and drafting the manuscript. XMW contributed to the concept and design of the study and for the final approved version, and supervise the study. ZTL analyzed the data and drafted the manuscript. YJL performed cell culture experiments and helped revise the manuscript. LS analyzed the data and organized the data. ZZ contributed to the concept and design of the study. YXZ critically revised the article and acquired the data. All authors read and approved the final manuscript.

\section{Ethics approval and consent to participate}

Not applicable.

\section{Patient consent for publication}

Not applicable.

\section{Competing interests}

The authors declare that they have no competing interests.

\section{References}

1. Parkin DM: Global cancer statistics in the year 2000. Lancet Oncol 2: 533-543, 2001.

2. Siegel R, Desantis C and Jemal A: Colorectal cancer statistics, 2014. CA Cancer J Clin 64: 104-117, 2014.

3. Chen W, Sun K, Zheng R, Zeng H, Zhang S, Xia C, Yang Z, Li H, Zou X and He J: Cancer incidence and mortality in China, 2014. Chin J Cancer Res 30: 1-12, 2018.

4. Lai HW, Wei JC, Hung HC and Lin CC: Tumor sidedness influences prognostic impact of lymph node metastasis in colon cancer patients undergoing curative surgery. Sci Rep 9: 19892, 2019.

5. Singh RK and Lokeshwar BL: The IL-8-regulated chemokine receptor CXCR7 stimulates EGFR signaling to promote prostate cancer growth. Cancer Res 71: 3268-3277, 2011.

6. Xue TC, Han D, Chen RX, Zou JH, Wang Y, Tang ZY and Ye SL: High expression of CXCR7 combined with alpha fetoprotein in hepatocellular carcinoma correlates with extra-hepatic metastasis to lung after hepatectomy. Asian Pac J Cancer Prev 12: 657-663, 2011.

7. Li XX, Zheng HT, Huang LY, Shi DB, Peng JJ, Liang L and Cai SJ: Silencing of CXCR7 gene represses growth and invasion and induces apoptosis in colorectal cancer through ERK and $\beta$-arrestin pathways. Int J Oncol 45: 1649-1657, 2014.

8. Miao Z, Luker KE, Summers BC, Berahovich R, Bhojani MS, Rehemtulla A, Kleer CG, Essner JJ, Nasevicius A,Luker GD, et al: CXCR7 (RDC1) promotes breast and lung tumor growth in vivo and is expressed on tumor-associated vasculature. Proc Natl Acad Sci USA 104: 15735-15740, 2007.

9. Floranović MP and Veličković LJ: Effect of CXCL12 and its receptors on unpredictable renal cell carcinoma. Clin Genitourin Cancer: Dec 4, 2019 (Epub ahead of print).

10. Atanes P, Hawkes RG, Olaniru OE, Ruz-Maldonado I, Amisten S and Persaud SJ: CXCL14 inhibits insulin secretion independently of CXCR4 or CXCR7 receptor activation or cAMP inhibition. Cell Physiol Biochem 52: 879-892, 2019.

11. Zhang $\mathrm{H}$, Wang $\mathrm{P}$, Zhang $\mathrm{X}$, Zhao $\mathrm{W}$, Ren $\mathrm{H}$ and $\mathrm{Hu} \mathrm{Z}$ : SDF1/CXCR7 signaling axis participates in angiogenesis in degenerated discs via the PI3K/AKT pathway. DNA Cell Biol 38: 457-467, 2019.

12. Balabanian K, Lagane B, Infantino S, Chow KY, Harriague J, Moepps B, Arenzana-Seisdedos F, Thelen M and Bachelerie F: The chemokine SDF-1/CXCL12 binds to and signals through the orphan receptor RDC1 in T lymphocytes. J Biol Chem 280: 35760-35766, 2005.

13. Daniel SK, Seo YD and Pillarisetty VG: The CXCL12CXCR4/CXCR7 axis as a mechanism of immune resistance in gastrointestinal malignancies. Semin Cancer Biol: Dec 23, 2019 (Epub ahead of print).

14. Wang J, Shiozawa Y, Wang J, Wang Y, Jung Y, Pienta KJ, Mehra R, Loberg R and Taichman RS: The role of CXCR7/RDC1 as a chemokine receptor for CXCL12/SDF-1 in prostate cancer. J Biol Chem 283: 4283-4294, 2008. 
15. Liberman J, Sartelet H, Flahaut M, Mühlethaler-Mottet A, Coulon A, Nyalendo C, Vassal G, Joseph JM and Gross N: Involvement of the CXCR7/CXCR4/CXCL12 axis in the malignant progression of human neuroblastoma. PLoS One 7: e43665, 2012.

16. Stacer AC, Fenner J, Cavnar SP, Xiao A, Zhao S, Chang SL, Salomonnson A, Luker KE and Luker GD: Endothelial CXCR7 regulates breast cancer metastasis. Oncogene 35: 1716-1724, 2016.

17. Wang HX, Tao LY, Qi KE, Zhang HY, Feng D, Wei WJ, Kong H, Chen TW, Lin QS and Chen DJ: Role of CXC chemokine receptor type 7 in carcinogenesis and lymph node metastasis of colon cancer. Mol Clin Oncol 3: 1229-1232, 2015.

18. Hao M, Zheng J, Hou K, Wang J, Chen X, Lu X, Bo J, Xu C, Shen K and Wang J: Role of chemokine receptor CXCR7 in bladder cancer progression. Biochem Pharmacol 84: 204-214, 2012.

19. Heinrich EL, Lee W, Lu J, Lowy AM and Kim J: Chemokine CXCL12 activates dual CXCR4 and CXCR7-mediated signaling pathways in pancreatic cancer cells. J Transl Med 10: $68,2012$.

20. Tachezy M, Zander H, Gebauer F, von Loga K, Pantel K, Izbicki JR and Bockhorn M: CXCR7 expression in esophageal cancer. J Transl Med 11: 238, 2013.

21. Liu Z, Yang L, Teng X, Zhang H and Guan H: The involvement of CXCR7 in modulating the progression of papillary thyroid carcinoma. J Surg Res 191: 379-388, 2014.

22. Wani N, Nasser MW, Ahirwar DK, Zhao H, Miao Z, Shilo K and Ganju RK: C-X-C motif chemokine 12/C-X-C chemokine receptor type 7 signaling regulates breast cancer growth and metastasis by modulating the tumor microenvironment. Breast Cancer Res 16: R54, 2014.

23. Zhao ZW, Fan XX, Song JJ, Xu M, Chen MJ, Tu JF, Wu FZ, Zhang DK, Liu L, Chen L, et al: ShRNA knock-down of CXCR7 inhibits tumour invasion and metastasis in hepatocellular carcinoma after transcatheter arterial chemoembolization. J Cell Mol Med 21: 1989-1999, 2017.

24. Li X, Wang X, Li Z, Zhang Z and Zhang Y: Chemokine receptor 7 targets the vascular endothelial growth factor via the AKT/ERK pathway to regulate angiogenesis in colon cancer. Cancer Med 8: 5327-5340, 2019

25. Livak KJ and Schmittgen TD: Analysis of relative gene expression data using real-time quantitative PCR and the 2(-Delta Delta C(T)) method. Methods 25: 402-408, 2001

26. Bergers $\mathrm{G}$ and Benjamin LE: Tumorigenesis and the angiogenic switch. Nat Rev Cancer 3: 401-410, 2003.

27. Balkwill F: Cancer and the chemokine network. Nat Rev Cancer 4: 540-550, 2004.

28. Ben-Baruch A: Organ selectivity in metastasis: Regulation by chemokines and their receptors. Clin Exp Metastasis 25 345-356, 2008
29. Romain B, Hachet-Haas M, Rohr S, Brigand C, Galzi JL, Gaub MP, Pencreach E and Guenot D: Hypoxia differentially regulated CXCR4 and CXCR7 signaling in colon cancer. Mol Cancer 13: 58, 2014

30. Yu Y, Li H, Xue B, Jiang X, Huang K, Ge J, Zhang H and Chen B SDF-1/CXCR7 axis enhances ovarian cancer cell invasion by MMP-9 expression through p38 MAPK pathway. DNA Cell Biol 33: 543-549, 2014.

31. Qian T, Liu Y, Dong Y, Zhang L, Dong Y, Sun Y and Sun D: CXCR7 regulates breast tumor metastasis and angiogenesis in vivo and in vitro. Mol Med Rep 17: 3633-3639, 2018.

32. Kollmar O, Rupertus K, Scheuer C, Nickels RM, Haberl GC, Tilton B, Menger MD and Schilling MK: CXCR4 and CXCR7 regulate angiogenesis and CT26.WT tumor growth independent from SDF-1. Int J Cancer 126: 1302-1315, 2010.

33. Yang D, Dai T, Xue L, Liu X, Wu B, Geng J, Mao X, Wang R, Chen L and Chu X: Expression of chemokine receptor CXCR7 in colorectal carcinoma and its prognostic significance. Int J Clin Exp Pathol 8: 13051-13058, 2015

34. Guillemot E, Karimdjee-Soilihi B, Pradelli E, Benchetrit M, Goguet-Surmenian E, Millet MA, Larbret F, Michiels JF, Birnbaum D, Alemanno P, et al: CXCR7 receptors facilitate the progression of colon carcinoma within lung not within liver. Br J Cancer 107: 1944-1949, 2012.

35. Wang H, Tao L, Qi KE, Zhang H, Feng D, Wei W, Kong H, Chen T, Lin Q and Chen D: CXCR7 functions in colon cancer cell survival and migration. Exp Ther Med 10: 1720-1724, 2015.

36. Wang Y, Xu P, Qiu L, Zhang M, Huang Y and Zheng JC: CXCR7 participates in CXCL12-mediated cell cycle and proliferation regulation in mouse neural progenitor cells. Curr Mol Med 16: 738-746, 2016.

37. Kim HY, Lee SY, Kim DY, Moon JY, Choi YS, Song IC, Lee HJ, Yun HJ, Kim S and Jo DY: Expression and functional roles of the chemokine receptor CXCR7 in acute myeloid leukemia cells. Blood Res 50: 218-226, 2015.

38. Lin L, Han MM, Wang F, Xu LL, Yu HX and Yang PY: CXCR7 stimulates MAPK signaling to regulate hepatocellular carcinoma progression. Cell Death Dis 5: e1488, 2014.

39. Gebauer F, Tachezy M, Effenberger K, von Loga K, Zander H, Marx A, Kaifi JT, Sauter G, Izbicki JR and Bockhorn M: Prognostic impact of CXCR4 and CXCR7 expression in pancreatic adenocarcinoma. J Surg Oncol 104: 140-145, 2011.

This work is licensed under a Creative Commons Attribution-NonCommercial-NoDerivatives 4.0 International (CC BY-NC-ND 4.0) License. 